OPEN ACCESS

Edited by:

Matteo Elia Mangoni, Centre National de la Recherche

Scientifique (CNRS), France

Reviewed by:

Roberto $V$ Reyes,

University of Chile, Chile

Michel Negrerie,

École Polytechnique, France

${ }^{*}$ Correspondence:

Benito A. Yard

Benito.Yard@medma.uni-

heidelberg.de

${ }^{t}$ These authors have contributed equally to this work and share senior authorship

Specialty section:

This article was submitted to Pharmacology of lon Channels and

Channelopathies,

a section of the journal

Frontiers in Pharmacology

Received: 29 April 2021

Accepted: 24 August 2021

Published: 06 September 2021

Citation:

Zhang D, Krause BM, Schmalz H-G, Wohlfart $P$, Yard $B A$ and Schubert $R$ (2021) ET-CORM Mediated Vasorelaxation of Small Mesenteric Arteries: Involvement of Kv7

Potassium Channels.

Front. Pharmacol. 12:702392.

doi: 10.3389/fphar.2021.702392

\section{ET-CORM Mediated Vasorelaxation of Small Mesenteric Arteries: Involvement of Kv7 Potassium Channels}

\author{
Danfeng Zhang ${ }^{1,2}$, Bernhard M. Krause ${ }^{3}$, Hans-Günther Schmalz ${ }^{3}$, Paulus Wohlfart ${ }^{4}$, \\ Benito A. Yard ${ }^{1,5 * t}$ and Rudolf Schubert ${ }^{5,6 t}$ \\ ${ }^{1}$ Department of Nephrology, Endocrinology and Rheumatology, Fifth Medical Department of Medicine, Medical Faculty \\ Mannheim, University of Heidelberg, Mannheim, Germany, ${ }^{2}$ Department of Nephrology, the Second Hospital of Anhui Medical \\ University, Hefei, China, ${ }^{3}$ Department of Chemistry, University of Cologne, Cologne, Germany, ${ }^{4}$ Diabetes Research, Sanofi \\ Aventis Deutschland GmbH, Frankfurt, Germany, ${ }^{5}$ European Center of Angioscience (ECAS), Research Division Cardiovascular \\ Physiology, Medical Faculty Mannheim, Heidelberg University, Frankfurt, Germany, ${ }^{6}$ Physiology, Institute of Theoretical Medicine, \\ Medical Faculty, University of Augsburg, Augsburg, Germany
}

Although the vasoactive properties of carbon monoxide (CO) have been extensively studied, the mechanism by which $\mathrm{CO}$ mediates vasodilation is not completely understood. Through-out published studies on CO mediated vasodilation there is inconsistency on the type of $\mathrm{K}^{+}$-channels that are activated by $\mathrm{CO}$ releasing molecules (CORMs). Since the vasorelaxation properties of enzyme triggered CORMs (ET-CORMs) have not been studied thus far, we first assessed if ET-CORMs can mediate vasodilation of small mesenteric arteries and subsequently addressed the role of soluble guanylate cyclase (sGC) and that of K-channels herein. To this end, 3 different types of ETCORMs that either contain acetate (rac-1 and rac-4) or pivalate (rac-8) as ester functionality, were tested ex vivo on methoxamine pre-contracted small rat mesenteric arteries in a myograph setting. Pre-contracted mesenteric arteries strongly dilated upon treatment with both types of acetate containing ET-CORMs (rac-1 and rac-4), while treatment with the pivalate containing ET-CORM (rac-8) resulted in no vasodilation. Pretreatment of mesenteric arteries with the SGC inhibitor ODQ abolished rac-4 mediated vasodilation, similar as for the known SGC activator SNP. Likewise, rac-4 mediated vasodilation did not occur in KCL pretreated mesenteric arteries. Although mesenteric arteries abundantly expressed a variety of $\mathrm{K}^{+}$-channels only Kv7 channels were found to be of functional relevance for rac-4 mediated vasodilation. In conclusion the current results identified Kv7 channels as the main channel by which rac-4 mediates vasodilation. In keeping with the central role of Kv7 in the control of vascular tone and peripheral resistance these promising ex-vivo data warrant further in vivo studies, particularly in models of primary hypertension or cardiac diseases, to assess the potential use of ET-CORMs in these diseases.

Keywords: vasorelaxation, carbon monoxide, potassium channels, rat, mesenteric arteries 


\section{INTRODUCTION}

Carbon monoxide (CO), endogenously produced by heme oxygenases ( $\mathrm{HO})$, is considered to be an important signaling molecule participating in a variety of cellular functions (Romanski et al., 2012a; Olas, 2014; Naito et al., 2016). The interest for using $\mathrm{CO}$ as a potential therapeutic agent has increased considerably in the past decade as a number of in vitro and in vivo studies have corroborated the beneficial effect of CO in a variety of disease models (Guo et al., 2004; Musameh et al., 2007; Ferrándiz et al., 2008). Clinical trials to assess the feasibility and safety of therapeutic CO inhalation have been performed in patients with chronic obstructive pulmonary disease (NCT00122694) (Bathoorn et al., 2007) and in patients with sepsis-induced acute respiratory distress syndrome (NCT02425579) (Fredenburgh et al., 2018; Mayr et al., 2005).

While in phase I clinical studies CO was applied in its gaseous form, in recent years a number of different $\mathrm{CO}$ releasing molecules (CORMs) have been synthesized and successfully tested in in vitro and in vivo inflammation models. CORMs release $\mathrm{CO}$ either spontaneously or require specific triggering mechanisms. In order to deliver $\mathrm{CO}$ directly into cells and to gain a better control over $\mathrm{CO}$ release, we have introduced so called enzyme-triggered CORMs (ET-CORMs) (Romanski et al., 2011; Romanski et al., 2012a; Romanski et al., 2013). ET-CORMs are acyloxy-butadiene- $\mathrm{Fe}(\mathrm{CO})_{3}$ complexes that are relatively stable under physiological conditions. Once intracellular, the ester functionality of ET-CORMs is cleaved by hydrolytic enzymes (e.g., esterases), resulting in the formation of labile dienol iron carbonyl complexes that subsequently disintegrate under oxidative conditions to release $\mathrm{CO}$, ferric ions and the corresponding enones (Romanski et al., 2011). CO release can be influenced by the type and position of the ester substituent of the ET-CORM as well as by the mother compound from which it is derived (Romanski et al., 2013). This concept also allows the design of protease specific $\mathrm{CO}$ release, thus paving avenues for the implementation of cell specific CO delivery (Sitnikov et al., 2015).

The HO-1/CO system plays prominent biological roles in the vasculature. $\mathrm{CO}$ is an often under-appreciated signaling molecule, acting on a wide variety of signaling pathways that regulate vasodilation (Koçer et al., 2018), inflammation (Ryter and Choi, 2016) as well as angiogenesis (Choi et al., 2017). CO administration in its gaseous form appears to reduce the contractility of pre-contracted arteries which may prevent or mitigate the occurrence of vasoconstrictor mediated spasm of arterial grafts in coronary artery bypass surgery in a cGMP dependent manner (Wang et al., 1997a; Achouh et al., 2005). CO delivery via CORMs also has beneficial effects on the vasculature, e.g., blunting of placental ischemia induced hypertension (George et al., 2017) and improvement of cerebrovascular dysfunction caused by neonatal seizures (Liu et al., 2015). Yet, vessel relaxation mediated by gaseous CO or CORM-2 may differ in their mode of action as suggested by Decaluwé et al. (Decaluwé et al., 2012). They postulated that CO relaxes vessels through activation of $\mathrm{sGC}$ and/or calciumactivated $\mathrm{K}^{+}$-channels, while it seems that CORM- 2 induced vasodilatation much more depends on voltage-dependent rather than calcium-activated $\mathrm{K}^{+}$-channels. Participation of cGMP, potassium channels and nitric oxide (NO) has been postulated in the vasodilatory properties of the water soluble CORM-2 and CORM-3 (Al-Owais et al., 2017), yet the involvement of $\mathrm{NO}$ has been questioned by others (Failli et al., 2012; Alshehri et al., 2013). Because CO can cause concomitantly activation and inhibition of NO synthase, it seems that CORMs display context-dependent effects as they can directly dilate blood vessels, but also block NO-induced vasorelaxation (Alshehri et al., 2013).

Even though the role of $\mathrm{K}^{+}$-channels in $\mathrm{CO}$ mediated vasorelaxation is widely accepted, there exists controversy on the class of $\mathrm{K}^{+}$-channels by which this occurs. Whether different CORMs activate different $\mathrm{K}^{+}$-channels or if differences in $\mathrm{CO}$ mediated vasorelaxation are due to differences in the expression level of $\mathrm{K}^{+}$-channels in different vessels remains to be addressed. Based on the current understanding of the vasoactive properties of CO and CORMs, this study underlies the hypothesis that ETCORMs are able to cause vasodilation of pre-contracted resistance vessels in a sGC and $\mathrm{K}^{+}$-channel dependent manner. The hypothesis was tested by studying vascular responses of small rat mesenteric arteries ex-vivo.

\section{MATERIALS AND METHODS}

\section{Drugs}

Acyloxydiene complexes (ET-CORM) rac-1, rac-4 and rac-8 were synthesized as previously described (Romanski et al., 2011). Stock solutions were prepared in dimethyl sulfoxide (DMSO) and stored at $-20^{\circ} \mathrm{C}$. The parent ligand of $\mathrm{rac}-4,2$-cyclohexenone was included to assess whether vascular activity was mediated by released $\mathrm{CO}$ or by the by-products of $\mathrm{rac}_{-4}$ cleavage. Methoxamine, acetylcholine (both dissolved in $\mathrm{H}_{2} \mathrm{O}$ ), XE991 and glibenclamide (both dissolved in DMSO) were obtained from Sigma. Iberiotoxin and DPO-1 were obtained from Tocris (Wiesbaden-Norden-stadt, Germany). Stromatoxin (dissolved in $\mathrm{H}_{2} \mathrm{O}$ ) was obtained from Alomone Labs (Jerusalem, Israel). $\mathrm{BaCl}_{2}$ (dissolved in $\mathrm{H}_{2} \mathrm{O}$ ) was obtained from Riedel-de-Haën (Seelze, Germany).

\section{Animals}

Adult, 8- to 12-week-old, male Wistar rats were obtained from Janvier (France; RRID: RGD_13,508,588). The animals were provided with food and water ad libitum and housed in a room with a controlled temperature and a 12-h light-dark cycle in IVC cages. The use of laboratory animals and all procedures included in this study were in accordance with the NIH Guide for the care and Use of Laboratory Animals. Approval for the use of laboratory animals in this study was granted by a governmental committee on animal welfare (I-17/17).

\section{Vessel Preparation}

Rats were sacrificed under $\mathrm{CO}_{2}$ narcosis by decapitation. The mesentery was immediately removed and transferred to cold $\left(4^{\circ} \mathrm{C}\right)$ physiological salt solution (PSS) composed of (in $\mathrm{mM}$ ): $\mathrm{NaCl}$ 145; $\mathrm{KCl}$ 4.5; $\mathrm{CaCl}_{2}$ 0.1; $\mathrm{MgSO}_{4} 1.0 ; \mathrm{NaH}_{2} \mathrm{PO}_{4}$ 1.2; EDTA 
0.025; HEPES $5.0(\mathrm{pH}=7.4)$. Mesenteric arteries $(\sim 150 \mu \mathrm{m}$ diameter and $2 \mathrm{~mm}$ long) were dissected and cleaned off fat and connective tissue. Mesenteric artery rings were mounted in a wire myograph (model 610M, Danish Myo Technology, Denmark). The organ bath was filled with $5 \mathrm{ml}$ PSS consisting of (in mM) NaCl 120; $\mathrm{NaHCO}_{3} 26 ; \mathrm{KCl} 4.5 ; \mathrm{CaCl}_{2} 1.6 ; \mathrm{MgSO}_{4}$ 1.0; $\mathrm{NaH}_{2} \mathrm{PO}_{4}$ 1.2; D-glucose 5.5; EDTA 0.025; HEPES 5.0, was heated to $37^{\circ} \mathrm{C}$, and continuously oxygenated with carbogen $(95 \%$ $\mathrm{O}_{2} / 5 \% \mathrm{CO}_{2}$ ) to maintain $\mathrm{pH}$ at 7.4 . In some experiments, the endothelium of mesenteric artery rings was removed by scratching the lumen of the vessel gently with a rat whisker. The successful functional removal of the endothelium was confirmed by the absence of acetylcholine-induced vasodilation of $1 \mu \mathrm{mol} / \mathrm{L}$ methoxamine pre-contracted arteries. Each mesenteric artery segment underwent a normalization procedure before the experiment. In order to obtain optimal responses of the vessels, the segments were stretched stepwise to a diameter corresponding to $90 \%$ of the diameter the vessel would have at a transmural pressure of $100 \mathrm{mmHg}(13,3 \mathrm{kPa})$ using the Lab Chart DMT (Mulvany and Halpern, 1977) Normalization module. All data acquisition and analysis were performed using LabChart (AD Instruments, United States). Viability of the vessel preparations was determined with methoxamine at $10 \mu \mathrm{M}$ to test smooth muscle cell function. All drugs were added to the bath solution. Arterial tension is expressed as a percentage of the steady-state tension (100\%) generated by $10 \mu \mathrm{M}$ methoxamine.

\section{Gene Expression Analysis}

Mesenteric arteries were isolated as described above, snapfrozen in liquid nitrogen and stored at $-80^{\circ} \mathrm{C}$. Total RNA isolation was performed using the RNeasy RNA isolation kit according to the manufacturer's instruction. Further purification of RNA was performed according to the protocol provided by the manufacturer. The quantity and quality of the isolated RNA were controlled using an RNA 6000 nano kit (Agilent, Waldbronn, Germany). Only samples with an integrity RIN value $>7.5$ were used for further analysis. Reverse transcription was performed using a high capacity RNA-to-cDNA Kit (Applied Biosystems, Weiterstadt, Germany). Real-time PCR was performed on potassium ion channel genes in parallel using TaqMan microfluidic card technology in a Viia7 thermocycler (ThermoFisher, Darmstadt, Germany) with a maximum of 40 cycles. These cards contained wells for specific channel genes and five reference (housekeeping) genes. All TaqMan primers were tested before by dilution experiments and used only when amplification efficacies were close to $100 \%$. Threshold quantification cycles ( $\mathrm{Cq}$ values) were obtained for each gene delivered by the manufacturer's Viia7 software and further analyzed using the ArrayStudio software package (Version 9, Omicsoft Corporation, Research Triangle Park, NC, United States). The levels of gene expression were obtained by subtracting first from the individual $\mathrm{Cq}$ values a geometric average normalizing value of four reference genes, namely B2M, Eif2b1, Gusb, and Ywhaz. Relative expression was then calculated as potency of this difference in Cq with the basis of 2 .

\section{Statistics}

All data are presented as mean \pm SEM (standard error of the mean). The $n$-value given in the figures correspond to the number of animals tested. Differences between concentration-response relationships were tested by ANOVA for repeated measurements. The confidence level $p$ was set to 0.05 .

\section{RESULTS}

\section{Vascular Activities of Structurally Different ET-CORMs}

Since the positions of the ester functionality in ET-CORMs, as well as the mother compound from which they are derived, strongly influence their biological activity (Romanski et al., 2013), we first tested three structural different ET-CORMs (Figure 1) for vascular activity. The tested concentrations were chosen on the basis of preliminary experiments assessing the toxicity of these ET-CORMs. Pre-contracted mesenteric arteries strongly dilated upon treatment with both types of acetate containing ET-CORMs ( $r a c-1$, Figures 2A,B; rac-4, Figures 2C,D), while treatment with the pivalate containing ETCORM ( $r a c-8)$ resulted in no vasodilation (Figures 2E,F). For the former types of ET-CORMs vasodilation occurred irrespective of the presence or absence of the endothelium (Figures 2A-D). In order to focus on smooth muscle cell signaling all further experiments have been performed on endothelium-denuded vessels. Vasodilation appeared to be transient for rac-1, particularly in denuded arteries, whereas for $\mathrm{rac}_{\mathbf{4}} \mathbf{4}$ arteries remained dilated over the whole observation time.

\section{ET-CORM Mediated Vascular Activity Is Guanylyl Cyclase Dependent}

In as much as rac- $\mathbf{4}$ was most effective in inducing vasodilation at a relative low concentration compared to the other ET-CORMs tested, subsequent experiments to delineate the underlying mechanisms were only performed with rac-4. As shown in Figure $\mathbf{3 A}$, vasodilation by $\mathrm{rac}-\mathbf{4}$ occurred in a concentrationdependent manner. To exclude that vasodilation was mediated via the byproducts of rac-4 hydrolysis rather than $\mathrm{CO}, \mathrm{FeCl}_{2}$, $\mathrm{FeCl}_{3}$ and 2-cyclohexanone were applied to the vessels. None of these compounds lead to vasodilation (Figures 3B,C), suggesting that $\mathrm{CO}$ released from $\mathrm{rac}-\mathbf{4}$ is likely responsible for modulating vascular tone. Pre-treatment of mesenteric arteries with the guanylyl cyclase inhibitor ODQ abolished rac-4 mediated vasodilation (Figure 3D), similar as for the known guanylyl cyclase activator SNP (Figure 3E).

\section{ET-CORM Mediated Vascular Activity Is Mediated by Potassium Channels}

In order to address whether rac-4-induced vasodilation is mediated by potassium channels, mesenteric arteries were pre-treated with $50 \mathrm{mM} \mathrm{KCl}$. Under these conditions, the efflux of $\mathrm{K}^{+}$through potassium channels in smooth muscle cells is abolished due to a 
<smiles>CC(=O)OC1=CCC2(OCOCO)CCC1C2</smiles>

rac-1<smiles>CC(=O)Oc1ccccc1C(=O)OCc1ccccc1</smiles>

rac-4<smiles>CC(C)(C)C(=O)OC1=CCC(C(=O)O)C(OC(=O)C(C)(C)C)=C1</smiles>

rac-8

FIGURE 1 | Chemical structure of the ET-CORMs rac-1, rac-4, and rac-8.

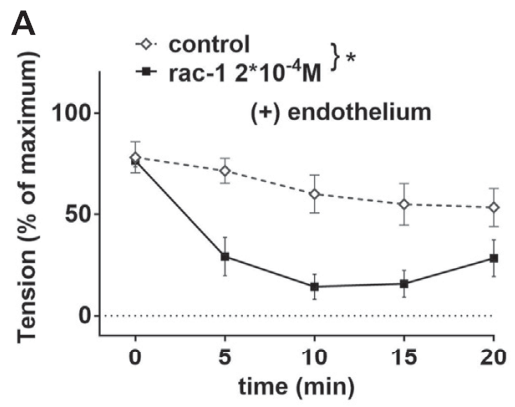

C

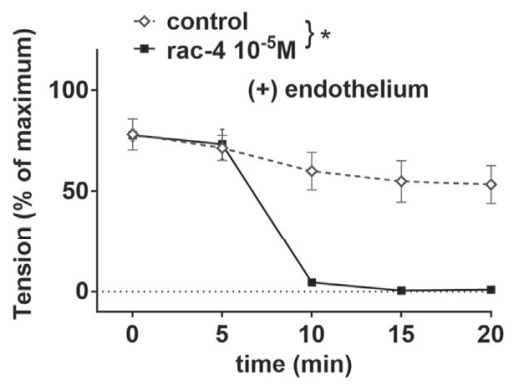

E

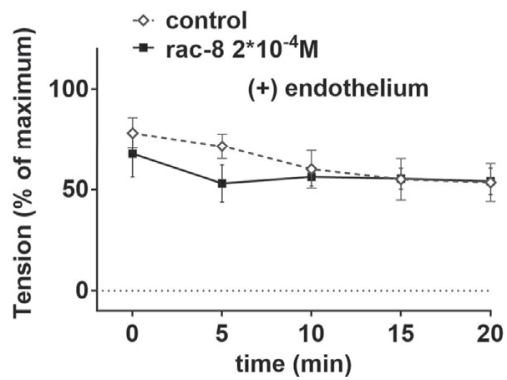

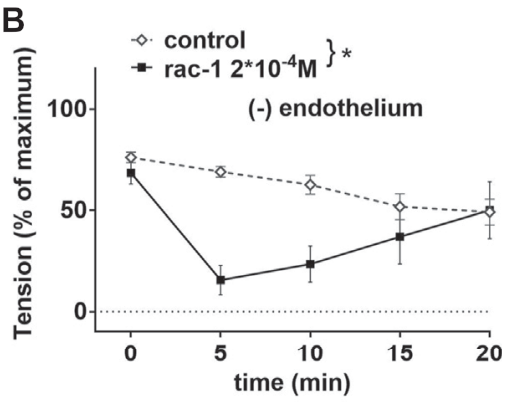

D

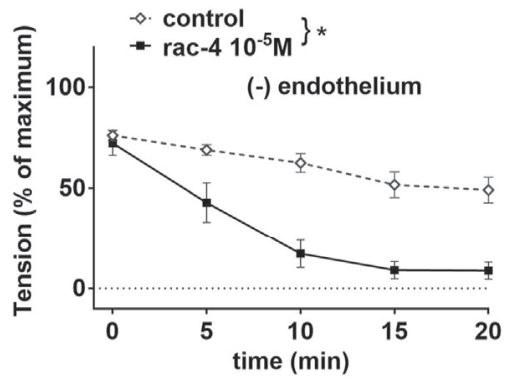

$\mathbf{F}$

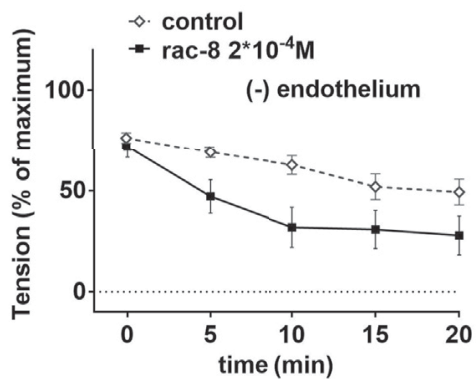

FIGURE 2 | Vascular activities of structurally different ET-CORMs on mesenteric arteries. (A) Effect of rac-1 (rac-1 $\left.2^{*} 10^{-4} \mathrm{M}\right)$ and of DMSO (control) on vessel tension induced by $10^{-6} \mathrm{M}$ methoxamine in endothelium-intact arteries. (repeated measures ANOVA, $\mathrm{n}=5, p<0.05$ ). (B) Effect of rac-1 (rac-1 $2^{*} 10^{-4} \mathrm{M}$ ) and of DMSO (control) on vessel tension induced by $10^{-6} \mathrm{M}$ methoxamine in endothelium-denuded arteries. (repeated measures ANOVA, $\mathrm{n}=5, p<0.05$ ). (C) Effect of rac-4 (rac-4 $10^{-5} \mathrm{M}$ ) and of DMSO (control) on vessel tension induced by $10^{-6} \mathrm{M}$ methoxamine in endothelium-intact arteries. (repeated measures ANOVA, $n=5, p<0.05$ ). (D) Effect of rac-4 (rac-4 10 $0^{-5} \mathrm{M}$ ) and of DMSO (control) on vessel tension induced by $10^{-6} \mathrm{M}$ methoxamine in endothelium-denuded arteries. (repeated measures ANOVA, $\mathrm{n}=5, p<0.05$ ). (E) Effect of rac-8 (rac-8 $2^{*} 10^{-4} \mathrm{M}$ ) and of DMSO (control) on vessel tension induced by $10^{-6} \mathrm{M}$ methoxamine in endothelium-intact arteries. (repeated measures ANOVA, $n=5, p=0.60)$. (F) Effect of rac-8 $\left(\right.$ rac $-82^{*} 10^{-4} \mathrm{M}$ ) and of DMSO (control) on vessel tension induced by $10^{-6} \mathrm{M}$ methoxamine in endotheliumdenuded arteries. (repeated measures ANOVA, $\mathrm{n}=5, p=0.06$ ).

lack of driving force for the ions, thereby eliminating the functionality of potassium channels. Rac-4 produced considerable relaxation of methoxamine pre-contracted mesenteric arteries (Figure 4A). An effect of rac-4 on $\mathrm{KCl}$ pre-contracted arteries was not detected (Figure 4B), indicating an involvement of potassium channels in the vasodilatory action of rac-4.

In subsequent experiments we sought to assess which potassium channels were mediating rac-4-induced 

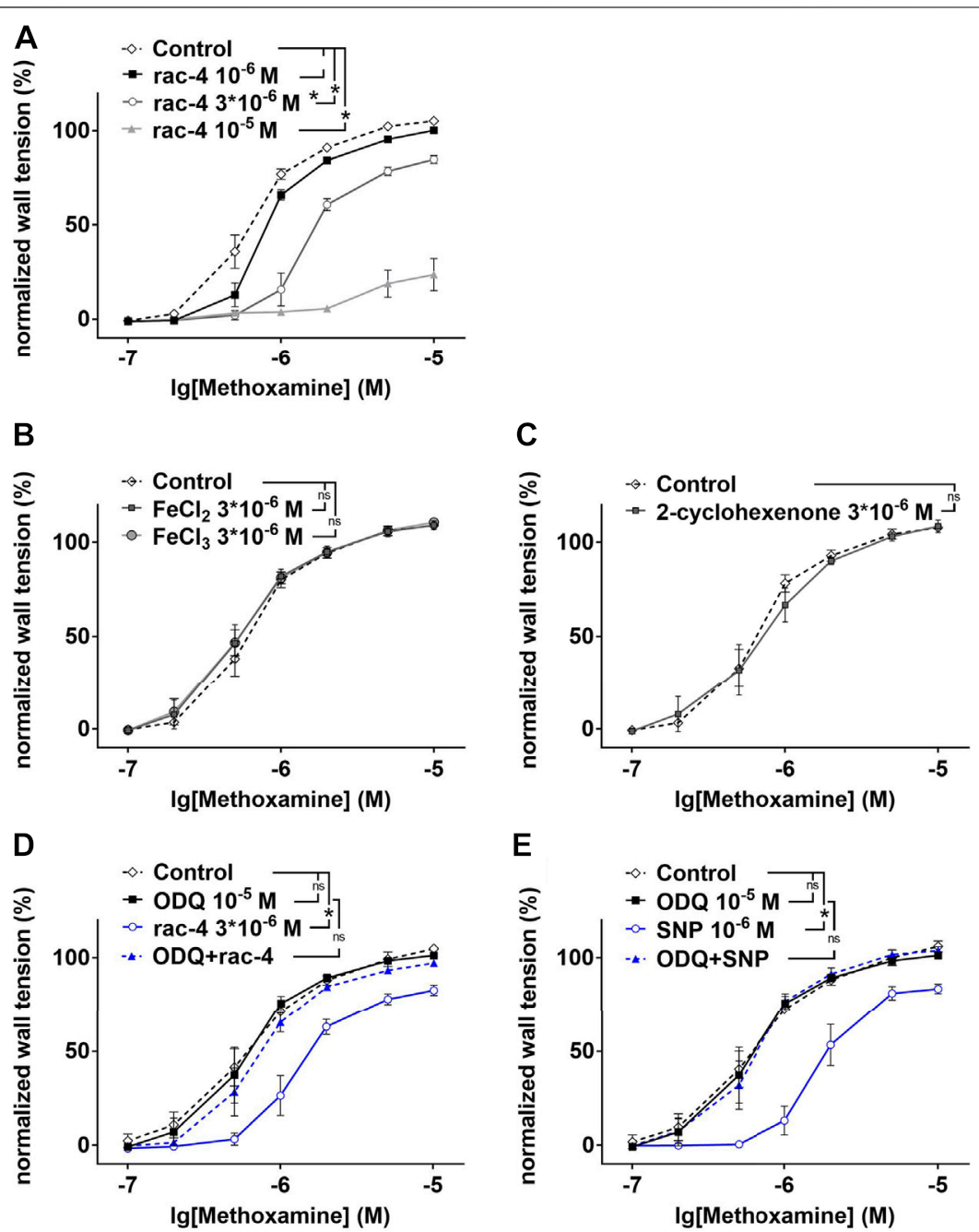

FIGURE 3 | Dilation of mesenteric arteries induced by rac-4 is guanylyl cyclase dependent. (A) Methoxamin-induced contraction in the absence of any substances (Control) and in the presence of different concentrations of rac-4 $\left(10^{-6} \mathrm{M}, 3^{\star} 10^{-6} \mathrm{M}, 10^{-5} \mathrm{M}\right)$. (repeated measures ANOVA, $n=6, p<0.05$, particular comparisons indicated in legend). (B) Methoxamin-induced contraction in the absence of any substances (Control) and in the presence of $3^{\star} 10^{-6} \mathrm{M} \mathrm{FeCl}_{2}$ and $\mathrm{FeCl}_{3}$, respectively. (repeated measures ANOVA, $\mathrm{n}=6, p=0.68$ and $p=0.53$ for $\mathrm{FeCl}_{2}$ and $\mathrm{FeCl}_{3}$, respectively). (C) Methoxamin-induced contraction in the absence of any substances (Control) and in the presence of $3^{\star} 10^{-6} \mathrm{M}$ 2-cyclohexenone. (repeated measures ANOVA, $\mathrm{n}=5, p=0.77$ ). (D) Methoxamin-induced contraction in the absence of any substances (Control), in the presence of $10^{-5} \mathrm{M} \mathrm{ODQ}$, in the presence of $3^{\star} 10^{-6} \mathrm{M} \mathrm{rac}-4$ and in the presence of the combination of ODQ and rac-4. (repeated measures ANOVA, $\mathrm{n}=6$, Control vs rac-4: $p<0.05$; Control vs ODQ: $p=0.79$; ODQ vs ODQ + rac-4: $p=0.26$ ). (E) Methoxamin-induced contraction in the absence of any substances (Control), in the presence of $10^{-5} \mathrm{M} \mathrm{ODQ}$, in the presence of $10^{-6} \mathrm{M} \mathrm{SNP}$ and in the presence of the combination of ODQ and SNP. (repeated measures ANOVA, $\mathrm{n}=6$, Control vs SNP: $p<0.05$; Control vs ODQ: $p=0.77$; ODQ vs ODQ + SNP: $p=0.90$ ).

vasodilation. To this end, we first determined gene expression levels of various potassium channels in mesenteric arteries by qPCR. As shown in Figure 5, Kv1 (KCNA), Kv2 (KCNB), Kv3 (KCNC), Kv7 (KCNQ), Kv11, Kir2, Kir6, BK (Kca1) and SK (Kca2) channels are abundantly expressed in these arteries. Of note, Kv3, Kv11, Kir2 and SK channels were not further explored because of a lack of specific inhibitors or a lack of published data suggesting their involvement in guanylyl cyclase-mediated vasodilation. The contribution of the other potassium channels to rac-4 mediated vasodilation was studied using specific channel inhibitors as depicted in Table $\mathbf{1 .}$

Further, mesenteric arteries were pre-treated with different combinations of potassium channel inhibitors leaving only Kir2,
Kir6, BK or Kv channels, respectively available (Table 1). When compared to the effect of its solvent DMSO, rac-4 induced only vasodilation when $\mathrm{Kv}$ channels were not inhibited (Figures 6A-D).

In order to identify the $\mathrm{Kv}$ channel subtype involved, mesenteric arteries were pre-treated with different combinations of potassium channel inhibitors leaving only Kv1, Kv2 or Kv7 channels available (Table 2). Rac-4 did not induce vasodilation compared to the effects of its solvent DMSO when only Kv1 (Figure 7A) or only Kv2 (Figure 7B) channels were available. In contrast, when only Kv7 channels were left available rac-4 was able to dilate the vessels (Figure 7C). In line with this, inhibition of Kv7 

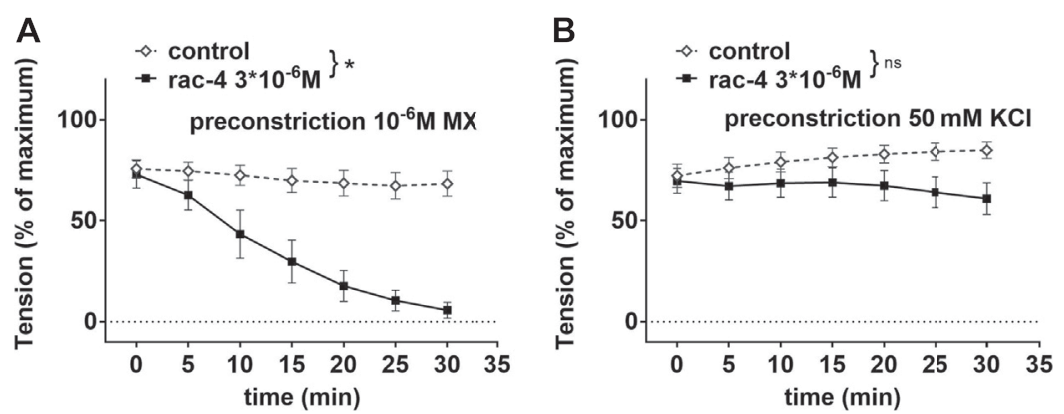

FIGURE 4 | Dilation of mesenteric arteries induced by rac-4 is K-channel dependent. (A) Effect of rac-4 (rac-4 $3^{\star} 10^{-6} \mathrm{M}$ ) and of DMSO (control) on vessel tension induced by $10^{-6} \mathrm{M}$ methoxamine. (repeated measures ANOVA, $n=6, p<0.05$ ). (B) Effect of rac-4 (rac-4 $3^{\star} 10^{-6} \mathrm{M}$ ) and of DMSO (control) on vessel tension induced by $50 \mathrm{mM} \mathrm{KCl}$. (repeated measures ANOVA, $\mathrm{n}=8, p=0.14$ ).

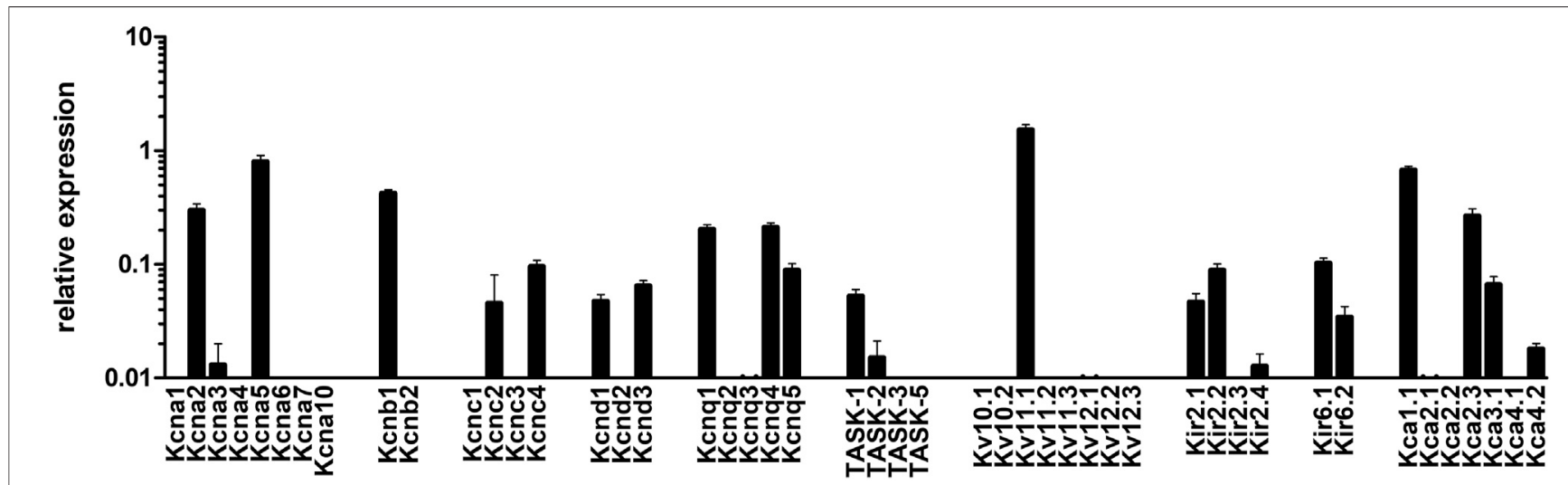

FIGURE 5 I mRNA expression of K-channels in mesenteric arteries. Relative expression of K (+)-channels assessed by realtime PCR with Taqman primers in intact mesenteric arteries. Normalized was performed as described in the method sections relative to the expression of five reference (housekeeping) genes, $\mathrm{B}_{2} \mathrm{M}$, Eif2b1, Gusb, Myh11, and Ywhaz ( $\mathrm{n}=8)$.

channels only by XE991 completely abolished rac-4 induced vasodilation (Figure 7D).

\section{DISCUSSION}

Carbon monoxide (CO) is an autocrine and paracrine vasodilator that can regulate tone in resistance vessels throughout the body (Leffler et al., 1999). While it has been suggested that gaseous CO mediates vasodilation through the activation of large- conductance $\mathrm{Ca}^{2+}$-activated potassium $\left(\mathrm{BK}_{\mathrm{Ca}}\right)$ channels as well as sGC present in arterial smooth muscle cells (Wang et al., 1997b; Jaggar et al., 2005), the role of the former has been questioned when applying the CO-donor CORM-2 (Wang et al., 1997b) but not CORM-A1 (Ryan et al., 2006) on femoral or renal interlobar arteries respectively. Whether this is due to differential activation of $\mathrm{K}^{+}$-channels by different CORMs or due to differences in the expression level of $\mathrm{K}^{+}$channels in different vessels is still elusive. The cytoprotective -, anti-inflammatory - and CO releasing properties of ET-CORMs

TABLE 1 | combination of potassium channel inhibitors used for leaving only a particular channel available.

Nr.

1

2

3
Combination of potassium channel inhibitors ${ }^{a}$

Iberiotoxin, XE991, DPO-1, STTX, Glibenclamid

Iberiotoxin, XE991, DPO-1, STTX, BaCl

XE991, DPO-1, STTX, Glibenclamid, $\mathrm{BaCl}_{2}$

Iberiotoxin, Glibenclamid, $\mathrm{BaCl}_{2}$
Available channel

Kir2

Kir6

$\mathrm{BK}$

KV
Blocked channel

BK, Kv7, Kv1, Kv2, Kir6 BK, Kv7, Kv1, Kv2, Kir2 Kv7, Kv1, Kv2, Kir6, Kir2 BK, Kir6, Kir2

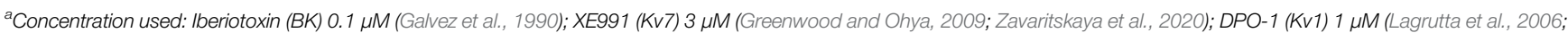

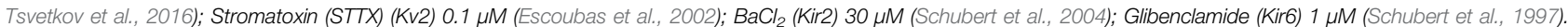



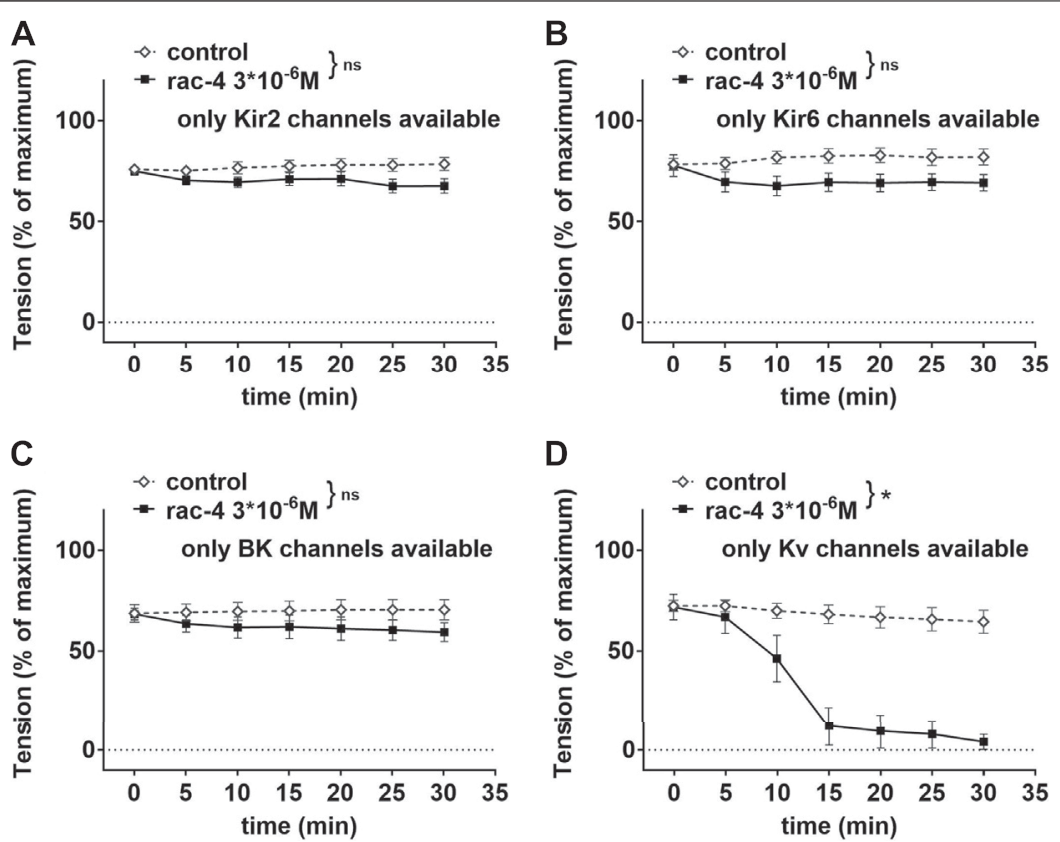

FIGURE 6 | Dilation of mesenteric arteries induced by rac-4 is Kv-channel dependent. (A) Effect of rac-4 (rac-4 $\left.3^{*} 10^{-6} \mathrm{M}\right)$ and of DMSO (control) on vessel tension induced by methoxamine together with a mixture of K-channel blockers $\left(10^{-7} \mathrm{M}\right.$ lberiotoxin, $3^{\star} 10^{-6} \mathrm{M}$ XE991, $10^{-6} \mathrm{M}$ DPO-1, $10^{-7} \mathrm{M}$ stromatoxin, $10^{-6} \mathrm{M}$ glibenclamide) leaving only Kir2 channels available. Of note, both treatments reached the same level of vessel tension. (repeated measures ANOVA: $\mathrm{n}=8$; $p=0.09$ ). (B) Effect of rac-4 (rac-4 $3^{*} 10^{-6} \mathrm{M}$ ) and of DMSO (control) on vessel tension induced by methoxamine together with a mixture of $\mathrm{K}$-channel blockers (10 ${ }^{-7} \mathrm{M}$

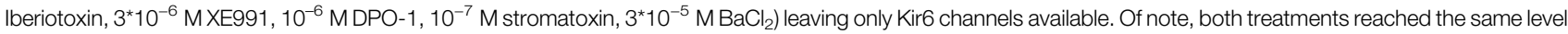
of vessel tension. (repeated measures ANOVA: $\mathrm{n}=8 ; p=0.07)$. (C) Effect of rac-4 $\left(\mathrm{rac}-\mathbf{4} 3^{\star} 10^{-6} \mathrm{M}\right.$ ) and of DMSO (control) on vessel tension induced by methoxamine

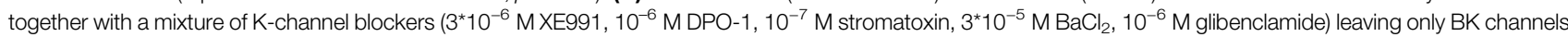
available. Of note, both treatments reached the same level of vessel tension. (repeated measures ANOVA: $n=7 ; p=0.28)$. (D) Effect of rac-4 (rac-4 $\left.3^{\star} 10^{-6} \mathrm{M}\right)$ and of

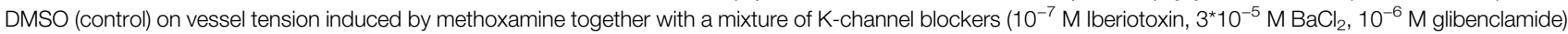
leaving only Kv channels available. Of note, both treatments reached the same level of vessel tension. (repeated measures ANOVA: $n=7 ; p<0.05$ ).

have been extensively studied (Ryan et al., 2006; Romanski et al., 2013; Stamellou et al., 2014), yet if ET-CORMs also are vasoactive on resistance vessels remains to be addressed. Based on the current understanding of the vasoactive properties of $\mathrm{CO}$ and CORMs, this study underlies the hypothesis that ET-CORMs are able to cause vasodilation of pre-contracted resistance vessels in a sGC and $\mathrm{K}^{+}$-channel dependent manner. The main findings of this study are as follows. 1) Pre-contracted mesenteric arteries strongly dilate upon treatment with both types of acetate containing ET-CORMs ( $r a c-1$ and $r a c-4)$, while treatment with the pivalate containing ET-CORM ( $r a c-8)$ resulted in no vasodilation. 2) Pre-treatment of mesenteric arteries with the sGC inhibitor ODQ abolished rac-4 mediated vasodilation, similar as for the known sGC activator SNP. 3) A variety of $\mathrm{K}^{+}$-channels are expressed in mesenteric arteries. The relative expression of each largely differs. 4) rac-4 mediated vasodilation occurs when only Kv7 channels are available and is blocked by the Kv7 inhibitor XE991. This suggests that Kv7 channels are the main potassium channels by which $\mathrm{rac}-\mathbf{4}$ mediates vasodilation in the vessels studied.

In previous studies, we revealed that the anti-inflammatory and cytoprotective properties of ET-CORMs strongly depend on their chemical structure, more specifically on the mother compound they are derived from and the type and position of the ester functionality that they harbor (Stamellou et al., 2014). In the present study, we show that this also holds true for the

TABLE 2 | Combination of Kv channel inhibitors used for leaving only a particular channel available.

\begin{tabular}{|c|c|c|c|}
\hline Nr. & Combination of potassium channel inhibitors ${ }^{a}$ & Available channel & Blocked channel \\
\hline 1 & Iberiotoxin, XE991, STTX, Glibenclamid, $\mathrm{BaCl}_{2}$ & Kv1 & $\mathrm{BK}, \mathrm{Kv} 7, \mathrm{Kv} 2$, Kir6, Kir2 \\
\hline 2 & Iberiotoxin, XE991, DPO-1, Glibenclamid, $\mathrm{BaCl}_{2}$ & Kv2 & BK, Kv7, Kv1, Kir6, Kir2 \\
\hline 3 & Iberiotoxin, DPO-1, STTX, Glibenclamid, $\mathrm{BaCl}_{2}$ & Kv7 & BK, Kv1, Kv2, Kir6, Kir2 \\
\hline 4 & XE991 & BK, Kv1, Kv2, Kir6, Kir2 & Kv7 \\
\hline
\end{tabular}

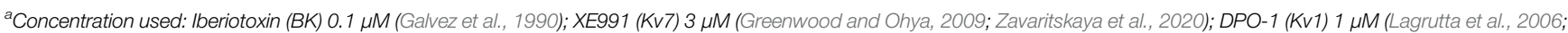

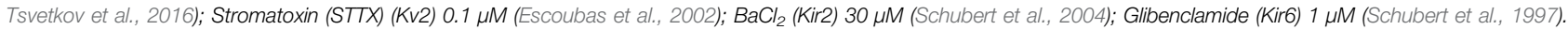



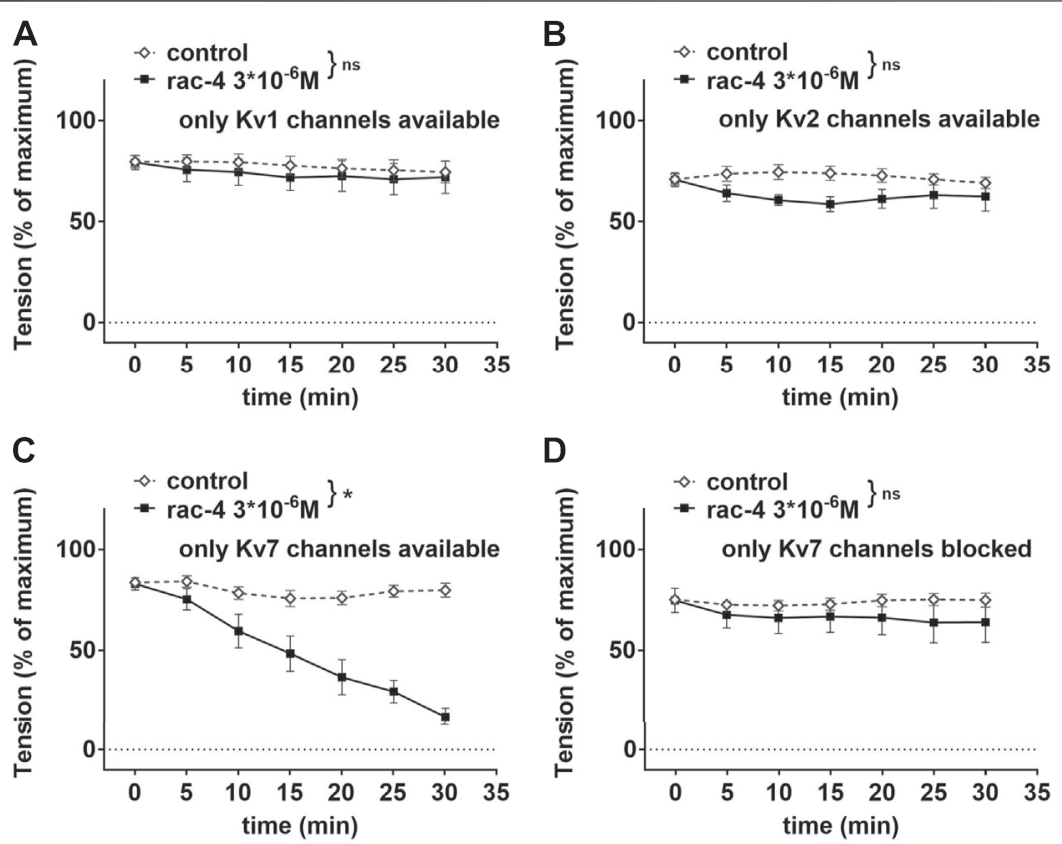

FIGURE 7 |Dilation of mesenteric arteries induced by rac-4 is Kv7-channel dependent. (A) Effect of rac-4 (rac-4 $3^{\star} 10^{-6}$ M) and of DMSO (control) on vessel tension

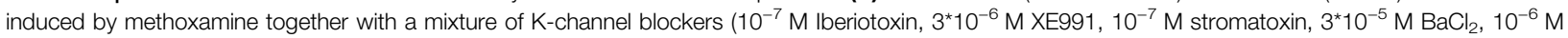
glibenclamide) leaving only Kv1 channels available. Of note, both treatments reached the same level of vessel tension. (repeated measures ANOVA: $\mathrm{n}=6$; $p=0.63)$. (B) Effect of rac-4 (rac-4 $3^{*} 10^{-6} \mathrm{M}$ ) and of DMSO (control) on vessel tension induced by methoxamine together with a mixture of $\mathrm{K}$-channel blockers (10 ${ }^{-7} \mathrm{M}$ Iberiotoxin, $3^{\star} 10^{-6} \mathrm{M}$ XE991, $10^{-6} \mathrm{M}$ DPO-1, $3^{\star} 10^{-5} \mathrm{M} \mathrm{BaCl}_{2}, 10^{-6} \mathrm{M}$ glibenclamide) leaving only Kv2 channels available. Of note, both treatments reached the same level of vessel tension. (repeated measures ANOVA: $\mathrm{n}=7 ; p=0.09)$. (C) Effect of rac-4 (rac-4 $3^{\star} 10^{-6} \mathrm{M}$ ) and of DMSO (control) on vessel tension induced by

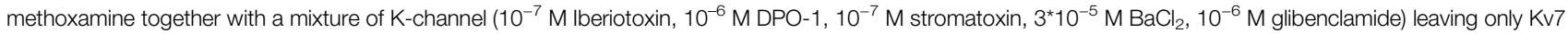
channels available. Of note, both treatments reached the same level of vessel tension. (repeated measures ANOVA: $n=10 ; p<0.05)$. (D) Effect of rac-4 (rac-4 $3^{\star} 10^{-6} \mathrm{M}$ ) and of DMSO (control) on vessel tension induced by methoxamine together with $3^{\star} 10^{-6} \mathrm{M}$ XE991 blocking only Kv7 channels. Of note, both treatments reached the same level of vessel tension. (repeated measures ANOVA: $\mathrm{n}=6 ; p=0.42$ ).

vasorelaxation properties of ET-CORMs. The efficacy of the acetate containing ET-CORMs, rac-1 and rac-4 was similar as reported for the inhibition of VCAM-1 (Romanski et al., 2013; Stamellou et al., 2014), with rac-4 being more effective compared to $\mathrm{rac}-\mathbf{1}$. This correlates with the slower release of $\mathrm{CO}$ from $\mathrm{rac}-\mathbf{1}$ (Romanski et al., 2012b). In contrast to the acetate containing ETCORMs, rac-8 was not able to cause vasodilation of precontracted mesenteric arteries, an unexpected finding based on previous published biological properties that were similar for rac$\mathbf{1}$ and rac-8. However, it should be emphasized that previous experiments with $\mathrm{rac}-\mathbf{8}$ were performed in human cells, which, compared to rat mesenteric arteries, may express different types of esterase enzymes for hydrolysis of the pivalate ester functionality. Moreover, uptake and hydrolysis of rac-8 by mesenteric arteries may require more time than the 30 -min time frame in which vasodilation was recorded. Previous publications have indeed demonstrated differences in hydrolysis efficiencies of acetate and pivalate propanolol prodrugs (Takahashi et al., 1995) and acyloxy nitroso compounds (Shoman et al., 2011) Likewise, the finding that pig liver esterase-induced $\mathrm{CO}$ release from pivalate containing ET-CORMs is much slower compared to that of the corresponding acetate containing ET-CORMs (Romanski et al., 2012b) corroborates the current results obtained with rac-1, rac-4 and rac-8. It should also be noted that the cytoprotective properties of ET-CORMs we reported previously were attributed to the inhibition of the NFkB-and activation of the Nrf2-Keap1 pathways (Ryan et al., 2006). These pathways are not involved in vasorelaxation.

Our study demonstrates that rac-4 mediates vasorelaxation in mesenteric arteries irrespective of a disrupted endothelium. In contrast, Alshehri et al. (Alshehri et al., 2013) reported that CORM-3 mediated vasorelaxation is partly endothelium dependent in the largest conduit vessel of the organism, the aorta. Differences in the vessel studied, concentrations used $(100 \mu \mathrm{M}$ vs. in $10 \mu \mathrm{M}, \mathrm{CORM}-3$ vs. rac-4) and intrinsic properties of the CORMs may underlie this discrepancy. In line with our current findings, most studies, including the study of Alshehri et al. (Alshehri et al., 2013), report that CO and CORM mediated vasorelaxation involves activation of the sGC (De Backer and Lefebvre, 2007; van der Sterren et al., 2011; Magierowska et al., 2019), even though sGC binds CO only with limited affinity (Martin et al., 2006). There are also studies however in which sGC did not participate in CO mediated vasorelaxation. As such ODQ did not inhibit, but rather potentiated endothelium independent relaxation by CORM-3 in WKY rat aorta rings (Achouh et al., 2005). Also, in the study of Decaluwé $\mathrm{K}$ et al. (Wang et al., 1997b) it was reported that vasorelaxation by gaseous 
CO strongly depends on sGC activation, while ODQ had no effect on CORM-2 induced relaxations of mice femoral arteries.

The proficiency of $\mathrm{CO}$ to regulate a variety of ion channels, e.g., calcium-activated $\mathrm{K}^{+}\left(\mathrm{BK}_{\mathrm{Ca}}\right)$ channels (Jaggar et al., 2005), voltageactivated $\mathrm{K}^{+}(\mathrm{Kv})$ channels (Dallas et al., 2011), and $\mathrm{Ca}^{2+}$ channels (Duckles et al., 2015), has been demonstrated in many studies and reflects the pluripotency of $\mathrm{CO}$ to participate in numerous physiological processes and pathologies. Likewise, the involvement of $\mathrm{K}^{+}$-channels in $\mathrm{CO}$ mediated vasorelaxation is unequivocally reported, albeit that there is ambiguity with respect to the class of $\mathrm{K}^{+}$-channels that are supposedly involved. While a number of studies have suggested an association between $\mathrm{HO}$ and $\mathrm{BK}_{\mathrm{Ca}}$ channels (Williams et al., 2004; Kooli et al., 2008) or their activation by CO (Wang et al., 1997a; Jaggar et al., 2002; Yi et al., 2010), other studies have postulated a role for voltage-gated $\mathrm{K}^{+}$channels (Kv1.5, Kv11.1) (Dong et al., 2007). Our data on rac-4 mediated vasorelaxation do not support the involvement of $\mathrm{BK}_{\mathrm{Ca}}$ channels, but instead we observed that $\mathrm{rac}-\mathbf{4}$ induced only significant vasodilation when $\mathrm{Kv} 7$ channels were not inhibited. Failure of rac-4 to activate $\mathrm{BK}_{\mathrm{Ca}}$ channels is unlikely due to differences in the relative expression between $\mathrm{BK}_{\mathrm{Ca}}$ (Kcal) and $\mathrm{Kv} 7$ (KCNQ) as the mRNA expression of the former was even slightly higher. The mechanism by which $\mathrm{CO}$ affects $\mathrm{BK}_{\mathrm{Ca}}$ is ambiguously discussed (Wang et al., 1997b; Jaggar et al., 2005) (De Backer and Lefebvre, 2007). In the studies of Jaggar et al. (Jaggar et al., 2005) $\mathrm{CO}$ activates $\mathrm{BK}_{\mathrm{Ca}}$ channels by binding to channel-bound heme, which alters the interaction between heme and the conserved heme-binding domain of the channel. Their data corroborate previous findings of Wang et al. (Wang et al., 1997b) who showed that the effect of gaseous CO on $\mathrm{K}_{\mathrm{Ca}}$ channels was not mediated by cGMP, but contradict the findings of De Backer et al. (De Backer and Lefebvre, 2007) in which CO mediated relaxation in circular smooth muscle strips of the murine gastric fundus and jejunum was sGC and $\mathrm{BK}_{\mathrm{Ca}}$ channel dependent. Due to different releasing mechanisms described for CORMs it is conceivable that steady-state intracellular CO concentrations will be reached faster by gaseous $\mathrm{CO}$ than by CORMs. This is particularly the case for ET-CORMs, which require further intra-cellular processing before $\mathrm{CO}$ is released (Romanski et al., 2012a). Hence, higher CO concentrations may favor the interaction with heme in $\mathrm{BK}_{\mathrm{Ca}}$, while the relatively small amount of $\mathrm{CO}$ released for rac-4 within the timeframe of the experiment may not suffice to activate $\mathrm{BK}_{\mathrm{Ca}}$ channels. We postulate that rac-4 stimulates $\mathrm{sGC}$, resulting in the activation of cGMP-dependent protein kinase (PKG) that subsequently phosphorylates and activates Kv7 channels. With the exception of Kv7.1 a conserved PKG phosphorylation site, i.e., KFKE (T/S)LRPY, is present in all other Kv7 members. PKG mediated Threonine or Serine phosphorylation of this site was predicted by the NetPhos 3.1 server. Assessment of cGMP and phosphorylation of Kv7 in mesenteric arteries is warranted to strengthen this assumption.

Ruthenium-containing carbonyl complexes such as tricabonyldichlororuthenium (II) dimer (CORM-2) or $[\mathrm{Ru}(\mathrm{CO})$ $3 \mathrm{Cl}$ (glycinate)] (CORM-3) can activate $\mathrm{K}^{+}$-channels directly and independent of CO release (Dong et al., 2007; Hou et al., 2008; Williams et al., 2008; Riddle and Walker, 2012; Gessner et al., 2017) Hydrolysis of $\mathrm{rac}_{-4} \mathbf{4}$ results in the generation of $\mathrm{CO}$, acetic acid, 2cyclohexanone and $\mathrm{Fe}^{2+/ 3+}$ in a molar ratio of 3:1 (CO: break-down product). Although our study does not provide formal proof that rac-4 mediated vasorelaxation exclusively involves $\mathrm{CO}$, none of the break-down products were able to mediate vasodilation of precontracted mesenteric arteries. It should be emphasized however, that hydrolysis of rac-4 occurs intra-cellular, yet it is not clear to what extent each of the break-down products are taken up by the mesenteric arteries when applied in the myograph.

In conclusion our current study has clearly demonstrated that the acetate containing ET-CORMs can mediate vasorelaxation of small mesenteric arteries in a sGC and Kv7 dependent manner. Both in rodents and human Kv7 proteins are expressed in the smooth muscle layer of visceral arteries ( $\mathrm{Ng}$ et al., 2011; Haick and Byron, 2016), where they regulate contractility and vascular resistance. If all Kv7 subtypes are activated by rac-4 remains to be addressed. While our study uses an ex-vivo model for assessing vascular responses, in vivo regulation of vascular tone is more complex. Yet, in keeping with the potential role of Kv7 channels in cardiovascular disease (Brenyo et al., 2012), hypertension (Carr et al., 2016), obesity and diabetes (Yamagata et al., 2011), these promising ex-vivo data warrant further in vivo studies in relevant disease models to assess the therapeutic potential of ET-CORMs.

\section{DATA AVAILABILITY STATEMENT}

The raw data supporting the conclusions of this article will be made available by the authors, without undue reservation.

\section{ETHICS STATEMENT}

The animal study was reviewed and approved by the Regierungspräsidium Karlsruhe, Abteilung 3.

\section{AUTHOR CONTRIBUTIONS}

BY and RS contributed to conception and design of the study. DZ performed the experiment except the PCR which was done by PW, BK and H-GS synthesised the ET-CORMs compound. DZ and SR performed the statistical analysis. DZ wrote the first draft of the manuscript. All authors contributed to manuscript revision, read, and approved the submitted version.

\section{FUNDING}

This project was supported by the Deutsche Forschungsgemeinschaft (IRTG 1874 DIAMICOM-SP 4 to PW, RS). DZ was supported by a scholarship from the China Scholarship Council (CSC; 201408080108).

\section{ACKNOWLEDGMENTS}

The authors thank Elke Deckert (Diabetes Research, Sanofi Aventis Deutschland $\mathrm{GmbH}$ ) for technical assistance. 


\section{REFERENCES}

Achouh, P., Simonet, S., Badier-Commander, C., Chardigny, C., VayssettesCourchay, C., Zegdi, R., et al. (2005). The Induction of Heme Oxygenase 1 Decreases Contractility in Human Internal Thoracic Artery and Radial Artery Grafts. J. Thorac. Cardiovasc. Surg. 130 (6), 1573-1580. doi:10.1016/ j.jtcvs.2005.07.055

Al-Owais, M5M., Hettiarachchi, N. T., Boyle, J. P., Scragg, J. L., Elies, J., Dallas, M. L., et al. (2017). Multiple Mechanisms Mediating Carbon Monoxide Inhibition of the Voltage-Gated K+ Channel Kv1.5. Cell Death Dis 8 (11), e3163. doi:10.1038/cddis.2017.568

Alshehri, A., Bourguignon, M. P., Clavreul, N., Badier-Commander, C., Gosgnach, W., Simonet, S., et al. (2013). Mechanisms of the Vasorelaxing Effects of CORM-3, a Water-Soluble Carbon Monoxide-Releasing Molecule: Interactions with eNOS. Naunyn Schmiedebergs Arch. Pharmacol. 386 (3), 185-196. doi:10.1007/s00210-012-0829-9

Bathoorn, E., Slebos, D. J., Postma, D. S., Koeter, G. H., van Oosterhout, A. J., van der Toorn, M., et al. (2007). Anti-inflammatory Effects of Inhaled Carbon Monoxide in Patients with COPD: a Pilot Study. Eur. Respir. J. 30 (6), 1131-1137. doi:10.1183/09031936.00163206

Brenyo, A. J., Huang, D. T., and Aktas, M. K. (2012). Congenital Long and Short QT Syndromes. Cardiology 122 (4), 237-247. doi:10.1159/000339537

Carr, G., Barrese, V., Stott, J. B., Povstyan, O. V., Jepps, T. A., Figueiredo, H. B., et al. (2016). MicroRNA-153 Targeting of KCNQ4 Contributes to Vascular Dysfunction in Hypertension. Cardiovasc. Res. 112 (2), 581-589. doi:10.1093/ cvr/cvw177

Choi, Y. K., Kim, J. H., Lee, D. K., Lee, K. S., Won, M. H., Jeoung, D., et al. (2017). Carbon Monoxide Potentiation of L-type Ca2+ Channel Activity Increases HIF-1 $\alpha$-independent VEGF Expression via an AMPKa/SIRT1-Mediated PGC1a/ERRa Axis. Antioxid. Redox Signal. 27 (1), 21-36. doi:10.1089/ars.2016.6684

Dallas, M. L., Boyle, J. P., Milligan, C. J., Sayer, R., Kerrigan, T. L., McKinstry, C., et al. (2011). Carbon Monoxide Protects against Oxidant-Induced Apoptosis via Inhibition of Kv2.1. Faseb j 25 (5), 1519-1530. doi:10.1096/fj.10-173450

De Backer, O., and Lefebvre, R. A. (2007). Mechanisms of Relaxation by Carbon Monoxide-Releasing Molecule-2 in Murine Gastric Fundus and Jejunum. Eur. J. Pharmacol. 572 (2-3), 197-206. doi:10.1016/j.ejphar.2007.06.005

Decaluwé, K., Pauwels, B., Verpoest, S., and Van de Voorde, J. (2012). Divergent Mechanisms Involved in CO and CORM-2 Induced Vasorelaxation. Eur. J. Pharmacol. 674 (2-3), 370-377. doi:10.1016/j.ejphar.2011.11.004

Dong, D. L., Zhang, Y., Lin, D. H., Chen, J., Patschan, S., Goligorsky, M. S., et al. (2007). Carbon Monoxide Stimulates the Ca2(+)-Activated Big Conductance K Channels in Cultured Human Endothelial Cells. Hypertension 50 (4), 643-651. doi:10.1161/HYPERTENSIONAHA.107.096057

Duckles, H., Al-Owais, M. M., Elies, J., Johnson, E., Boycott, H. E., Dallas, M. L., et al. (2015). T-type Ca2+ Channel Regulation by CO: A Mechanism for Control of Cell Proliferation. Adv. Exp. Med. Biol. 860, 291-300. doi:10.1007/ 978-3-319-18440-1_33

Escoubas, P., Diochot, S., Célérier, M. L., Nakajima, T., and Lazdunski, M. (2002). Novel Tarantula Toxins for Subtypes of Voltage-dependent Potassium Channels in the Kv2 and Kv4 Subfamilies. Mol. Pharmacol. 62 (1), 48-57. doi:10.1124/mol.62.1.48

Failli, P., Vannacci, A., Di Cesare Mannelli, L., Motterlini, R., and Masini, E. (2012). Relaxant Effect of a Water Soluble Carbon Monoxide-Releasing Molecule (CORM-3) on Spontaneously Hypertensive Rat Aortas. Cardiovasc. Drugs Ther. 26 (4), 285-292. doi:10.1007/s10557-012-6400-6

Ferrándiz, M. L., Maicas, N., Garcia-Arnandis, I., Terencio, M. C., Motterlini, R., Devesa, I., et al. (2008). Treatment with a CO-releasing Molecule (CORM-3) Reduces Joint Inflammation and Erosion in Murine Collagen-Induced Arthritis. Ann. Rheum. Dis. 67 (9), 1211-1217. doi:10.1136/ard.2007.082412

Fredenburgh, L. E., Perrella, M. A., Barragan-Bradford, D., Hess, D. R., Peters, E., Welty-Wolf, K. E., et al. (2018). A Phase I Trial of Low-Dose Inhaled Carbon Monoxide in Sepsis-Induced ARDS. JCI Insight 3 (23). doi:10.1172/ jci.insight.124039

Galvez, A., Gimenez-Gallego, G., Reuben, J. P., Roy-Contancin, L., Feigenbaum, P., Kaczorowski, G. J., et al. (1990). Purification and Characterization of a Unique, Potent, Peptidyl Probe for the High Conductance Calcium-Activated
Potassium Channel from Venom of the Scorpion Buthus Tamulus. J. Biol. Chem. 265 (19), 11083-11090. doi:10.1016/s0021-9258(19)38560-6

George, E. M., Cockrell, K., Arany, M., Stec, D. E., Rimoldi, J. M., Gadepalli, R. S. V., et al. (2017). Carbon Monoxide Releasing Molecules Blunt Placental IschemiaInduced Hypertension. Am. J. Hypertens. 30 (9), 931-937. doi:10.1093/ajh/ hpx070

Gessner, G., Sahoo, N., Swain, S. M., Hirth, G., Schönherr, R., Mede, R., et al. (2017). CO-independent Modification of $\mathrm{K}+$ Channels by Tricarbonyldichlororuthenium(II) Dimer (CORM-2). Eur. J. Pharmacol. 815, 33-41. doi:10.1016/j.ejphar.2017.10.006

Greenwood, I. A., and Ohya, S. (2009). New Tricks for Old Dogs: KCNQ Expression and Role in Smooth Muscle. Br. J. Pharmacol. 156 (8), 1196-1203. doi:10.1111/j.1476-5381.2009.00131.x

Guo, Y., Stein, A. B., Wu, W. J., Tan, W., Zhu, X., Li, Q. H., et al. (2004). Administration of a CO-releasing Molecule at the Time of Reperfusion Reduces Infarct Size In Vivo. Am. J. Physiol. Heart Circ. Physiol. 286 (5), H1649-H1653. doi:10.1152/ajpheart.00971.2003

Haick, J. M., and Byron, K. L. (2016). Novel Treatment Strategies for Smooth Muscle Disorders: Targeting Kv7 Potassium Channels. Pharmacol. Ther. 165, 14-25. doi:10.1016/j.pharmthera.2016.05.002

Hou, S., Xu, R., Heinemann, S. H., and Hoshi, T. (2008). The RCK1 High-Affinity $\mathrm{Ca} 2+$ Sensor Confers Carbon Monoxide Sensitivity to Slo1 BK Channels. Proc. Natl. Acad. Sci. U S A. 105 (10), 4039-4043. doi:10.1073/pnas.0800304105

Jaggar, J. H., Leffler, C. W., Cheranov, S. Y., Tcheranova, D., E, S., and Cheng, X. (2002). Carbon Monoxide Dilates Cerebral Arterioles by Enhancing the Coupling of $\mathrm{Ca} 2+$ sparks to Ca2+-Activated K+ Channels. Circ. Res. 91 (7), 610-617. doi:10.1161/01.res.0000036900.76780.95

Jaggar, J. H., Li, A., Parfenova, H., Liu, J., Umstot, E. S., Dopico, A. M., et al. (2005). Heme Is a Carbon Monoxide Receptor for Large-Conductance Ca2+-Activated K+ Channels. Circ. Res. 97 (8), 805-812. doi:10.1161/ 01.RES.0000186180.47148.7b

Kooli, A., Kermorvant-Duchemin, E., Sennlaub, F., Bossolasco, M., Hou, X., Honoré, J. C., et al. (2008). trans-Arachidonic Acids Induce a Heme Oxygenase-dependent Vasorelaxation of Cerebral Microvasculature. Free Radic. Biol. Med. 44 (5), 815-825. doi:10.1016/j.freeradbiomed.2007.11.006

Koçer, G., Nasircilar Ülker, S., and Şentürk, Ü. K. (2018). The Contribution of Carbon Monoxide to Vascular Tonus. Microcirculation 25 (7), e12495. doi:10.1111/micc. 12495

Lagrutta, A., Wang, J., Fermini, B., and Salata, J. J. (2006). Novel, Potent Inhibitors of Human Kv1.5 K+ Channels and Ultrarapidly Activating Delayed Rectifier Potassium Current. J. Pharmacol. Exp. Ther. 317 (3), 1054-1063. doi:10.1124/ jpet.106.101162

Leffler, C. W., Nasjletti, A., Yu, C., Johnson, R. A., Fedinec, A. L., and Walker, N. (1999). Carbon Monoxide and Cerebral Microvascular Tone in Newborn Pigs. Am. J. Physiol. 276 (5), H1641-H1646. doi:10.1152/ajpheart.1999.276.5.H1641

Liu, J., Fedinec, A. L., Leffler, C. W., and Parfenova, H. (2015). Enteral Supplements of a Carbon Monoxide Donor CORM-A1 Protect against Cerebrovascular Dysfunction Caused by Neonatal Seizures. J. Cereb. Blood Flow Metab. 35 (2), 193-199. doi:10.1038/jcbfm.2014.196

Magierowska, K., Korbut, E., Hubalewska-Mazgaj, M., Surmiak, M., Chmura, A., Bakalarz, D., et al. (2019). Oxidative Gastric Mucosal Damage Induced by Ischemia/reperfusion and the Mechanisms of its Prevention by Carbon Monoxide-Releasing Tricarbonyldichlororuthenium (II) Dimer. Free Radic. Biol. Med. 145, 198-208. doi:10.1016/j.freeradbiomed.2019.09.032

Martin, E., Berka, V., Bogatenkova, E., Murad, F., and Tsai, A. L. (2006). Ligand Selectivity of Soluble Guanylyl Cyclase: Effect of the Hydrogen-Bonding Tyrosine in the Distal Heme Pocket on Binding of Oxygen, Nitric Oxide, and Carbon Monoxide. J. Biol. Chem. 281 (38), 27836-27845. doi:10.1074/ jbc.M601078200

Mayr, F. B., Spiel, A., Leitner, J., Marsik, C., Germann, P., Ullrich, R., et al. (2005) Effects of Carbon Monoxide Inhalation during Experimental Endotoxemia in Humans. Am. J. Respir. Crit. Care Med. 171 (4), 354-360. doi:10.1164/ rccm.200404-446OC

Mulvany, M. J., and Halpern, W. (1977). Contractile Properties of Small Arterial Resistance Vessels in Spontaneously Hypertensive and Normotensive Rats. Circ. Res. 41 (1), 19-26. doi:10.1161/01.res.41.1.19

Musameh, M. D., Green, C. J., Mann, B. E., Fuller, B. J., and Motterlini, R. (2007). Improved Myocardial Function after Cold Storage with Preservation Solution 
Supplemented with a Carbon Monoxide-Releasing Molecule (CORM-3). J. Heart Lung Transpl. 26 (11), 1192-1198. doi:10.1016/j.healun.2007.08.005

Naito, Y., Takagi, T., Uchiyama, K., Katada, K., and Yoshikawa, T. (2016). Multiple Targets of Carbon Monoxide Gas in the Intestinal Inflammation. Arch. Biochem. Biophys. 595, 147-152. doi:10.1016/j.abb.2015.06.020

Ng, F. L., Davis, A. J., Jepps, T. A., Harhun, M. I., Yeung, S. Y., Wan, A., et al. (2011). Expression and Function of the K+ Channel KCNQ Genes in Human Arteries. Br. J. Pharmacol. 162 (1), 42-53. doi:10.1111/j.1476-5381.2010.01027.x

Olas, B. (2014). Carbon Monoxide Is Not Always a Poison Gas for Human Organism: Physiological and Pharmacological Features of CO. Chem. Biol. Interact 222, 37-43. doi:10.1016/j.cbi.2014.08.005

Riddle, M. A., and Walker, B. R. (2012). Regulation of Endothelial BK Channels by Heme Oxygenase-Derived Carbon Monoxide and Caveolin-1. Am. J. Physiol. Cel Physiol 303 (1), C92-c101. doi:10.1152/ajpcell.00356.2011

Romanski, S., Kraus, B., Guttentag, M., Schlundt, W., Rücker, H., Adler, A., et al. (2012). Acyloxybutadiene Tricarbonyl Iron Complexes as Enzyme-Triggered CO-releasing Molecules (ET-CORMs): a Structure-Activity Relationship Study. Dalton Trans. 41 (45), 13862-13875. doi:10.1039/c2dt30662j

Romanski, S., Kraus, B., Guttentag, M., Schlundt, W., Rücker, H., Adler, A., et al. (2012). Acyloxybutadiene Tricarbonyl Iron Complexes as Enzyme-Triggered CO-releasing Molecules (ET-CORMs): a Structure-Activity Relationship Study. Dalton Trans. 41 (45), 13862-13875. doi:10.1039/c2dt30662j

Romanski, S., Kraus, B., Schatzschneider, U., Neudörfl, J. M., Amslinger, S., and Schmalz, H. G. (2011). Acyloxybutadiene Iron Tricarbonyl Complexes as Enzyme-Triggered CO-releasing Molecules (ET-CORMs). Angew. Chem. Int. Ed. Engl. 50 (10), 2392-2396. doi:10.1002/anie.201006598

Romanski, S., Stamellou, E., Jaraba, J. T., Storz, D., Krämer, B. K., Hafner, M., et al. (2013). Enzyme-triggered CO-releasing Molecules (ET-CORMs): Evaluation of Biological Activity in Relation to Their Structure. Free Radic. Biol. Med. 65, 78-88. doi:10.1016/j.freeradbiomed.2013.06.014

Ryan, M. J., Jernigan, N. L., Drummond, H. A., McLemore, G. R., Rimoldi, J. M., Poreddy, S. R., et al. (2006). Renal Vascular Responses to CORM-A1 in the Mouse. Pharmacol. Res. 54 (1), 24-29. doi:10.1016/j.phrs.2006.01.012

Ryter, S. W., and Choi, A. M. (2016). Targeting Heme Oxygenase-1 and Carbon Monoxide for Therapeutic Modulation of Inflammation. Transl Res. 167 (1), 7-34. doi:10.1016/j.trsl.2015.06.011

Schubert, R., Krien, U., Wulfsen, I., Schiemann, D., Lehmann, G., Ulfig, N., et al. (2004). Nitric Oxide Donor Sodium Nitroprusside Dilates Rat Small Arteries by Activation of Inward Rectifier Potassium Channels. Hypertension 43 (4), 891-896. doi:10.1161/01.HYP.0000121882.42731.6b

Schubert, R., Serebryakov, V. N., Mewes, H., and Hopp, H. H. (1997). Iloprost Dilates Rat Small Arteries: Role of K(ATP)- and K(Ca)-channel Activation by cAMP-dependent Protein Kinase. Am. J. Physiol. 272 (3 Pt 2), H1147-H1156. doi:10.1152/ajpheart.1997.272.3.H1147

Shoman, M. E., DuMond, J. F., Isbell, T. S., Crawford, J. H., Brandon, A., Honovar, J., et al. (2011). Acyloxy Nitroso Compounds as Nitroxyl (HNO) Donors: Kinetics, Reactions with Thiols, and Vasodilation Properties. J. Med. Chem. 54 (4), 1059-1070. doi:10.1021/jm101432z

Sitnikov, N. S., Li, Y., Zhang, D., Yard, B., and Schmalz, H. G. (2015). Design, Synthesis, and Functional Evaluation of CO-releasing Molecules Triggered by Penicillin G Amidase as a Model Protease. Angew. Chem. Int. Ed. Engl. 54 (42), 12314-12318. doi:10.1002/anie.201502445

Stamellou, E., Storz, D., Botov, S., Ntasis, E., Wedel, J., Sollazzo, S., et al. (2014). Different Design of Enzyme-Triggered CO-releasing Molecules (ETCORMs) Reveals Quantitative Differences in Biological Activities in Terms of Toxicity and Inflammation. Redox Biol. 2, 739-748. doi:10.1016/ j.redox.2014.06.002
Takahashi, K., Tamagawa, S., Sakano, H., Katagi, T., and Mizuno, N. (1995). Effects of the Ester Moiety on Stereoselective Hydrolysis of Several Propranolol Prodrugs in Rat Tissues. Biol. Pharm. Bull. 18 (10), 1401-1404. doi:10.1248/ bpb.18.1401

Tsvetkov, D., Tano, J. Y., Kassmann, M., Wang, N., Schubert, R., and Gollasch, M. (2016). The Role of DPO-1 and XE991-Sensitive Potassium Channels in Perivascular Adipose Tissue-Mediated Regulation of Vascular Tone. Front. Physiol. 7, 335. doi:10.3389/fphys.2016.00335

van der Sterren, S., Kleikers, P., Zimmermann, L. J., and Villamor, E. (2011). Vasoactivity of the Gasotransmitters Hydrogen Sulfide and Carbon Monoxide in the Chicken Ductus Arteriosus. Am. J. Physiol. Regul. Integr. Comp. Physiol. 301 (4), R1186-R1198. doi:10.1152/ajpregu.00729.2010

Wang, R., Wang, Z., and Wu, L. (1997). Carbon Monoxide-Induced Vasorelaxation and the Underlying Mechanisms. Br. J. Pharmacol. 121 (5), 927-934. doi:10.1038/sj.bjp.0701222

Wang, R., Wu, L., and Wang, Z. (1997). The Direct Effect of Carbon Monoxide on KCa Channels in Vascular Smooth Muscle Cells. Pflugers Arch. 434 (3), 285-291. doi:10.1007/s004240050398

Williams, S. E., Brazier, S. P., Baban, N., Telezhkin, V., Müller, C. T., Riccardi, D., et al. (2008). A Structural Motif in the C-Terminal Tail of Slo1 Confers Carbon Monoxide Sensitivity to Human BK Ca Channels. Pflugers Arch. 456 (3), 561-572. doi:10.1007/s00424-007-0439-4

Williams, S. E., Wootton, P., Mason, H. S., Bould, J., Iles, D. E., Riccardi, D., et al. (2004). Hemoxygenase-2 Is an Oxygen Sensor for a Calcium-Sensitive Potassium Channel. Science 306 (5704), 2093-2097. doi:10.1126/ science. 1105010

Yamagata, K., Senokuchi, T., Lu, M., Takemoto, M., Fazlul Karim, M., Go, C., et al. (2011). Voltage-gated K+ Channel KCNQ1 Regulates Insulin Secretion in MIN6 $\beta$-cell Line. Biochem. Biophys. Res. Commun. 407 (3), 620-625. doi:10.1016/j.bbrc.2011.03.083

Yi, L., Morgan, J. T., and Ragsdale, S. W. (2010). Identification of a Thiol/disulfide Redox Switch in the Human BK Channel that Controls its Affinity for Heme and CO. J. Biol. Chem. 285 (26), 20117-20127. doi:10.1074/jbc.M110.116483

Zavaritskaya, O., Dudem, S., Ma, D., Rabab, K. E., Albrecht, S., Tsvetkov, D., et al. (2020). Vasodilation of Rat Skeletal Muscle Arteries by the Novel BK Channel Opener GoSlo Is Mediated by the Simultaneous Activation of BK and $\mathrm{Kv} 7$ Channels. Br. J. Pharmacol. 177 (5), 1164-1186. doi:10.1111/bph.14910

Conflict of Interest: PW was employed by Sanofi Aventis Deutschland GmbH.

The remaining authors declare that the research was conducted in the absence of any commercial or financial relationships that could be construed as a potential conflict of interest.

Publisher's Note: All claims expressed in this article are solely those of the authors and do not necessarily represent those of their affiliated organizations, or those of the publisher, the editors and the reviewers. Any product that may be evaluated in this article, or claim that may be made by its manufacturer, is not guaranteed or endorsed by the publisher.

Copyright (c) 2021 Zhang, Krause, Schmalz, Wohlfart, Yard and Schubert. This is an open-access article distributed under the terms of the Creative Commons Attribution License (CC BY). The use, distribution or reproduction in other forums is permitted, provided the original author(s) and the copyright owner(s) are credited and that the original publication in this journal is cited, in accordance with accepted academic practice. No use, distribution or reproduction is permitted which does not comply with these terms. 